\title{
Anesthetic management of a patient with undiagnosed paraganglioma
}

\section{-a case report-}

\author{
In Soo Han, Yee-Suk Kim, Joo-Hyun Yoo, Sung Soo Lim, and Tae Kwane Kim \\ Department of Anesthesiology and Pain Medicine, The Catholic University of Korea, Bucheon St. Mary's Hospital, Bucheon, Korea
}

Retroperitoneal paragangliomas are uncommon neuroendocrine tumors which are derived from extra-adrenal paraganglioma with various clinical signs and symptoms. Although most extra-adrenal paragangliomas are histologically benign, some tumors can synthesize and secrete excess catecholamine from the tumor. Excessive production of catecholamine causes numerous cardiovascular manifestations such as severe hypertension, cardiomyopathy, cardiac arrhythmias, and even multiorgan failure. It can lead to high risks of morbidity and mortality, especially in patients who are unrecognized or not adequately prepared. We present a female patient who was preoperatively undiagnosed of secreting retroperitoneal paraganglioma that caused cardiac tachyarrhythmia and severe intraopertive hypertension not controlled by usual antihypertensive agents. A secreting extra-adrenal paraganglioma should be included in differential diagnosis for patient who have incidentaloma and show wide range of hypertension with hemodynamic instability that is not well controlled by common antihypertensive drugs. (Korean J Anesthesiol 2013; 65: 574-577)

Key Words: Catecholamine, Hypertensive crisis, Paraganglioma.

Paragangliomas are rare catecholamine-producing tumors that arise from chromaffin cells of the sympathetic ganglia, and are known as extra-adrenal pheochromocytoma [1-4]. Paraganglions are widely distributed near or within the autonomic nervous system (ANS) in a variety of retroperitoneal sites in the sympathetic ganglia of various viscera [5]. Therefore they were found anywhere along the sympathetic chain from the base of the skull and neck to the pelvis, prostate gland and bladder $[1-4,6]$. Most extra-adrenal paragangliomas are histologically benign but some extra-adrenal paragngliomas can synthesize, store, and secrete catecholamines from the tumor. Excessive catecholamine production causes life-threatening cardiovascular complications such as severe hypertension, cardiac arrhythmia, cardiomyopathy, myocardial infarction, and pulmonary edema [2]. But most of extra- adrenal paraganglioma are rarely diagnosed preoperatively for their rarity and nonspecific signs and symptoms [4]. Sometimes, extra-adrenal paraganglioma can be discovered only after apparent during or after procedures or

Received: June 19, 2012. Revised: 1st, August 13, 2012; 2nd, November 8, 2012. Accepted: November 8, 2012.

Corresponding author: Tae Kwane Kim, M.D., Department of Anesthesiology and Pain Medicine, The Catholic University of Korea, Bucheon St. Mary's Hospital, 327, Sosa-ro, Wonmi-gu, Bucheon 420-717, Korea. Tel: 82-32-340-2158, Fax: 82-32-340-2255, E-mail: 3tkkim@catholic.ac.kr (c) This is an open-access article distributed under the terms of the Creative Commons Attribution Non-Commercial License (http:// creativecommons.org/licenses/by-nc/3.0/), which permits unrestricted non-commercial use, distribution, and reproduction in any medium, provided the original work is properly cited. 
interventions that provoke release of catecholamines from the tumor. In such situations, endocrine emergency can occur with an unpredictable course and hemodynamic instability during surgery, especially in patients who have not been appropriately prepared for surgery. Here we present a patient who was found with an incidentaloma during total abdominal hysterectomy. It resulted in marked blood pressure fluctuations and cardiac arrhythmia during the surgery and an unsuspected extra-adrenal paraganglioma was diagnosed.

\section{Case Report}

A 55-year-old female patient (weight $52 \mathrm{~kg}$, height $155 \mathrm{~cm}$ ) with multiple myoma was admitted for transabdominal hysterectomy (TAH). She suffered from severe dysmenorrhea and menorrhagia for several years. The patient had reported intermittent chest tightness, feeling of palpitations and a headache prior to admission. She had no history of diabetes, hypertension or any other systemic disease. At admission she had vital signs of blood pressure 130/75 $\mathrm{mmHg}$, pulse rate 81 beats/min, respiratory rate 20 times $/ \mathrm{min}$ and body temperature $36.3^{\circ} \mathrm{C}$. Preoperative laboratory tests were within normal limit with the exception of severe anemia (hemoglobin $=5.1 \mathrm{~g} / \mathrm{dl}$, hematocrit $=19.5 \%$ ). An abdominal magnetic resonance imaging (MRI) showed multiple and variable sized myomas and two simple hepatic cysts (Fig. 1). She received 4 pints of packed red cells (PRC) for over three days to correct the anemia in preparation for surgery .

Upon arrival to the operating room, she seemed to be anxious. Standard monitoring with electrocardiogram, pulse oximetry, and noninvasive blood pressure were applied before the

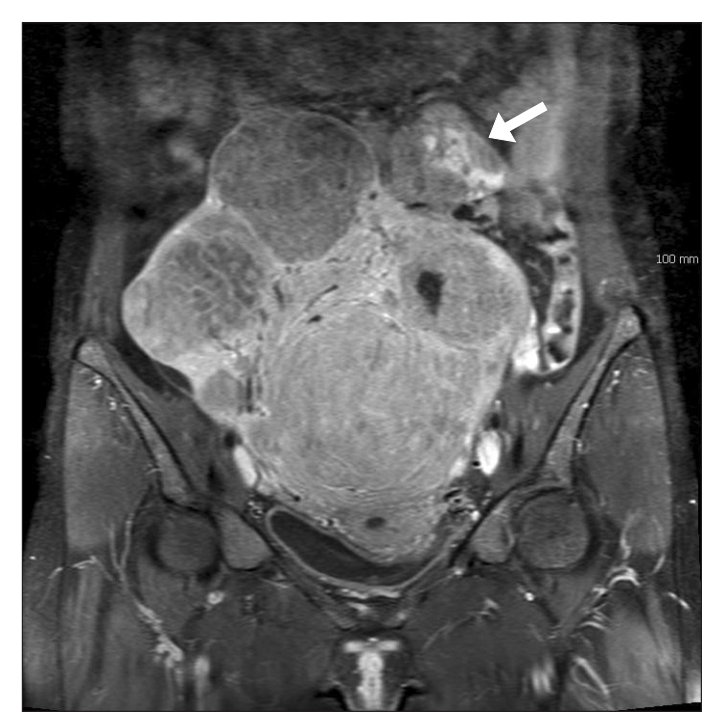

Fig. 1. Magnetic resonance imaging of a $5.5 \mathrm{~cm} \times 4.5 \mathrm{~cm} \times 5 \mathrm{~cm}$ secreting extra-adrenal paraganglioma with central lesion in para-aortic space (indicated by the arrow). induction of anesthesia. The initial vital signs were a blood pressure (BP) of 180/105 mmHg, pulse 77 beats/min, normal sinus rhythm on electrocardiogram (ECG) and arterial saturation of $99 \%$. To reduce anxiety, $3 \mathrm{mg}$ of midazolam was injected and general anesthesia was induced with propofol and remifentanil using a target-controlled infusion (TCI) system. After lidocaine administration, the target effect-site concentration (Ce) of propofol $4 \mu \mathrm{g} / \mathrm{ml}$ and remifentanil $4 \mathrm{ng} / \mathrm{ml}$ were started with 100 $\% \mathrm{O}_{2}$ and rocuronium $0.6 \mathrm{mg} / \mathrm{kg}$ was administered and used to facilitate tracheal intubation. Total intravenous anesthesia (TIVA) with propofol-remifentanil-50 $\% \mathrm{~N}_{2} \mathrm{O}$ in $\mathrm{O}_{2}$ was used for anesthetic maintenance. The target Ce of propofol was 2.5-3.5 $\mu \mathrm{g} / \mathrm{ml}$ and of remifentanil 2.5-3.0 $\mathrm{ng} / \mathrm{ml}$, respectively. The value of bispectral index (BIS) was maintained in the 35-45.

During the surgical exploration for TAH, a retroperitoneal encapsulated hard mass measuring $5.5 \times 4.5 \times 5 \mathrm{~cm}$ sized was found incidentally with huge uterine myomas $(20 \times 18 \mathrm{~cm})$. It lay at the para-arotic space along L3 vertebra with adhesion to the aorta. The operation for TAH began and the patient stayed hemodynamically stable as surgery proceeded. Approximately 135 min after abdominal hysterectomy started, a surgical excision for a retroperitoneal mass was continued a general surgery team. When the surgeon manipulated the retroperitoneal mass, the patient's BP suddenly increased to $220 / 130 \mathrm{mmHg}$ with a pulse rate of 140 (beats/min). The patient showed with frequent bigeminy on the ECG. The depth of anesthesia was deepened by increasing the Ce of propofol from $2.5-3.5 \mu \mathrm{g} / \mathrm{ml}$ to $4.5-6.0$ $\mu \mathrm{g} / \mathrm{ml}$ and remifentanil from $2.5-3.0 \mathrm{ng} / \mathrm{ml}$ to $4.5-5.0 \mathrm{ng} / \mathrm{ml}$, respectively. The value of BIS decreased from $40-50$ to the range of 25-30. But the blood pressure continued to rise reaching 180 $\mathrm{mmHg}$ for systolic and $100 \mathrm{mmHg}$ for diastolic. To control the increased $\mathrm{BP}$ and pulse rates, a continuous infusion of nicardipine $(2.0 \mathrm{mg} / \mathrm{hr})$ was started and an intermittent bolus of labetalol (15 mg of labetalol in three doses of $5 \mathrm{mg}$ each) with additional esmolol (total $30 \mathrm{mg}$ ) also used. However these treatments were not effective and the BP still remained at 170-180 $\mathrm{mmHg}$ for systolic and 95-100 $\mathrm{mmHg}$ for diastolic with increased heart rates in the range of 115-125 (beats/min) whenever the surgeon directly manipulated the mass. Radial arterial line was inserted after a modified Allen's test to monitor the labile BP and arrhythmia and to draw arterial blood gas (ABG) analysis sample. The ABG analysis revealed $\mathrm{pH}$ of 7.46, $\mathrm{PaCO}_{2} 33 \mathrm{mmHg}, \mathrm{PaO}_{2}$ $246 \mathrm{mmHg}$, and oxygen saturation $98 \%$ on $\mathrm{FiO}_{2}$ 0.5. Despite the increased anesthetic depth and anti-hypertensive therapy, the BP remained a wide range $\mathrm{BP}$ of $170-100 \mathrm{mmHg} / 60-80 \mathrm{mmHg}$. It was difficult to control due to the frequent swing between hypertension and hypotension. Therefore we highly suspected an unrecognized ectopic pheochromocytoma.

The retroperitoneal mass was completely removed approximately 60 min. Following the tumor removal, the BP decreased 


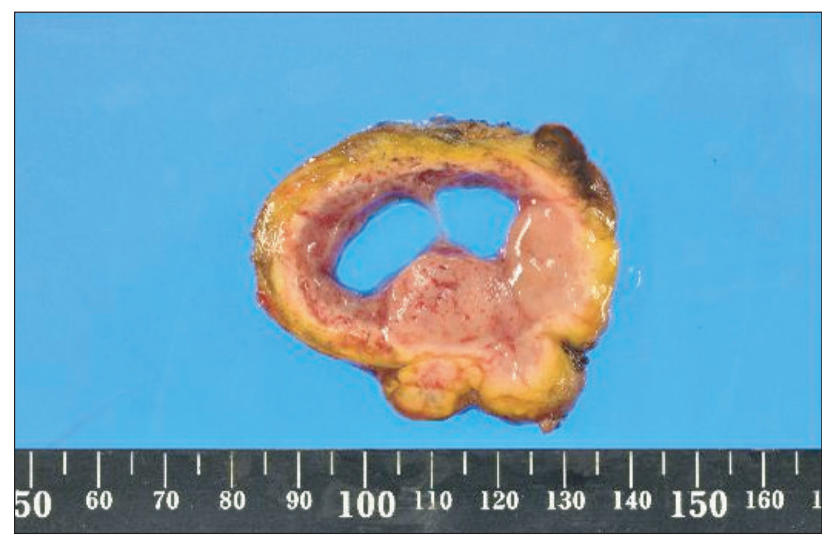

Fig. 2. Excised paraganglioma.

to as low as $75-85 \mathrm{mmHg} / 45-50 \mathrm{mmHg}$ and there was a slight increased heart rate 90 (beats/min) but it remained as low state despite fluid administration. When $2100 \mathrm{ml}$ of fluid was administered during the whole period of anesthesia (300 min), $420 \mathrm{ml}$ of crystalloid was administered at the time of retroperitoneal paraganglioma removal. After the removal of retroperitoneal mass, we administrated $500 \mathrm{ml}$ of volume expander and 2 pints of PRC and started a continuous dopamine infusion $(5 \mathrm{mcg} / \mathrm{kg} /$ $\mathrm{min}$ ) with intermittent phenylephrine $50-100 \mathrm{mcg}$ bolus injection to improve the patient's hemodynamic status. The estimated blood loss during the TAH was about $250 \mathrm{ml}$ and $200 \mathrm{ml}$ for the retroperitoneal mass. The mean urine output was $140 \mathrm{ml} / \mathrm{hr}$ and the total was $700 \mathrm{ml}$. After surgery, the patient showed BP 80-85 $\mathrm{mmHg}$ for systolic and 50-60 $\mathrm{mmHg}$ for diastolic and pulse 90 beats/min and the patient sent to the intensive care unit for close monitoring. The mass confirmed histopatholgically as an extraadrenal paraganglioma a week later (Fig. 2).

\section{Discussion}

Extra-adrenal paraganglia are rare chromaffin cell tumors that develop from neural crest cells $[1,3,5]$. Those that grow within the adrenal medulla are known as pheochromocytoma whereas extra-adrenal pheochromocytoma arise outside of the adrenal gland [1,5]. Extra-adrenal paraganglioma represent $10-18 \%$ of all chromaffin tissue-related tumors $[1,4]$. Pheochromocytoma and secreting extra-adrenal paraganglioma are the cause of the secondary hypertension in approximately $0.1 \%$ of hypertensive patients and the prevalence is estimated to be 1 per 100,000 persons per year or less [7]. Unlike pheochromocytoma, which have been described as having a $10 \%$ malignancy rate, paraganglioma, especially the abdominal extra-adrenal have a higher rate of malignancy ranging from $14 \%$ to as high as $50 \%$ [1] and retroperitoneal paragangliomas have a more genetic background $[1,3,4,8]$. Therefore genetic testing should be of- fered to patients diagnosed with extra-adrenal paraganglioma, particularly in patients who are young, have multiple tumors, or have a family history of malignancy [3]. However, in the absence of typical hypertension or for its rarity and nonspecific signs and symptoms, and diagnosis may be delayed or overlooked. Instead, most patients presented with mass effect related symptoms or incidentally from imaging studies such as a CT or MRI for other clinical conditions $[2,4]$. Only $20 \%$ of extra-adrenal paragangliomas have been discovered due to hyper-functioning tumors [4].

In the presented case, the retroperitoneal paraganglioma was discovered incidentally in the para-arotic spaces during a surgical exploration. Preoperatively the retroperitoneal mass was not recognized due to the fused and huge sized uterine myomas and its anatomic location on MRI findings. At first, the retroperitoneal mass was misdiagnosed as an ordinary simple mass. But the location of the retroperitoneal mass was very close to the aorta and it showed severe labile hypertension with mass manipulation, excessive tachycardia (140 beats/min), and cardiac rhythm changes (ventricular premature contracture) occurred due to loaded catecholamines. Furthermore, this severe hypertension was not well controlled by commonly used antihypertensive agents. These findings lead us to be suspicious of secreting extra-adrenal paraganglioma.

The classic triad of catecholamine excess is sweating, tachycardia and headache but the clinical presentation of extra-adrenal paraganglioma varies widely. They included tremor, pallor, panic attack, weight loss, hyperglycemia or hematuria in bladder paraganglioma. Recently Lim et al. [6] reported a hypertensive crisis experience during a transurethral resection in a paraganglioma of the bladder misdiagnosed as a simple hemangioma. The clinical presentations are highly variable and non-specific to diagnosis. It can sometimes be confused as other disease such as hyperthyroidism, panic attacks, hypoglycemia and alcohol withdrawal symptoms. Therefore these diseases should be differentiated for a secreting extra-adrenal paraganglioma [9]. Hypertension is the typical presentation and the majority of patients have some form of hypertension but approximately 5-15\% are normotensive [3]. Hypertension occurs spontaneously or as provoked by physical stress such as pain, anxiety, intubation, skin incision and increased abdominal pressure during surgery [10]. Hypertension associated with a secreting paraganglioma is primarily due to increased total peripheral resistance, mainly due to norephinephrine [7,9]. On the other hand pheochromocytoma may produce either norepinephrine or mainly ephinephrine which act potentially in $\beta_{2}-$ adrenal receptors of the skeletal muscle vasculature causing vasodilation that results in hypotension [11]. This difference in secretory pattern is related to the presence of phenylethanolamine $\mathrm{N}$-methyltransferase which converts norepinephrine to epinephrine [8]. The best screening test for a functional extra-adrenal paraganglioma is sampling 
of $24 \mathrm{hr}$ unine metanephrines. This test has a sensitivity of 89.9 $\%$ and specificity of $99 \%$ [1]. In the presented case, the patient's level of $24 \mathrm{hr}$ urinary excretion of fractionated metanephrine was $198.5 \mu \mathrm{g} /$ day (normal range: 52.0-341.0 $\mu \mathrm{g} /$ day) and normetanephrine was $543.0 \mu \mathrm{g} /$ day (normal: $88.0-444.0 \mu \mathrm{g} /$ day) at the 7 th postoperative day. A histological diagnosis confirmed that the mass was an extra-adrenal paraganglioma.

Surgical excision is an effective treatment approach and the prognosis is excellent if complete tumor removal can be achieved. But undiagnosed extra-adrenal paraganglioma without adequate drugs treatment can lead to potentially fatal hypertensive crisis. Wide swing in arterial pressure can be occurred as a result of a contracted intravascular volume [2]. Therefore the effect of excessive circulating catecholamine and adequate volume status should be reversed to prior state of an operation with combined $\alpha$ - and $\beta$-adrenergic blockade. In the present case, the patient persistently showed low BP after tumor removal even though fluid was administered to compensate blood loss. She needed vasopressors postoperatively as in other cases. This hypotension may be ascribed to abrupt fall in catecholamine which leaded to a sudden dilation of the vasculature and to profound hypoten- sion. The possibility of residual effects of previous used drugs of nicardipine or labetalol cannot also be ruled out. We controlled hypertensive responses with deepening of anesthesia levels and calcium channel blockers instead of short-acting agents such as sodium nitoprusside. Recently the clinical benefits of a calcium channel blocker due to potent vasodilatory action and partial suppression of catecholamine release from pheochromocytoma have been reported [12], but use of long-acting vasoactive medications compared to short acting could exacerbate an unstable hemodynamic instability potentially limited patients. When wide and precipitating swing in the $\mathrm{BP}$ and heart rate, more short- acting vasoactive drugs rather than long-acting drugs are preferred and recommended [1]. A secreting extra-adrenal paraganglioma may lead to an important life-threatening emergency situation without adequate preparation. The BP can reach very high values and compromise vital functions. This excessive hypertension can become unmanageable by common treatments. In this situation, a thoracic or abdominal incidentaloma should be questioned to be a catecholamine-producing tumor such as pheochromocytoma or secreting extra-adreanl paragnaglioma during surgical manipulation.

\section{References}

1. Lee JA, Duh QY. Sporadic paraganglioma. World J Surg 2008; 32: 683-7.

2. Renard J, Clerici T, Licker M, Triponez F. Pheochromocytoma and abdominal paraganglioma. J Visc Surg 2011; 148: e409-16.

3. Joynt KE, Moslehi JJ, Baughman KL. Paragangliomas: etiology, presentation, and managememnt. Cardiol Rev 2009; 17: 159-64.

4. Young WF Jr. Paragangliomas: clinical overview. Ann N Y Acad Sci 2006; 1073: 21-9.

5. Cunningham SC, Suh HS, Winter JM, Montgomery E, Schulick RD, Cameron JL, et al. Retroperitoenal paraganglioma: single-institution experience and review of the literature. J Gastrointest Surg 2006; 10: 1156-63.

6. Lim YH, Rhee WJ, Choi SR, Park SW, Chung CJ. Intraoperative hypertension in a patient with undiagnosed pheochromocytoma under spinal anesthesia. Korean J Anesthesiol 2008 ; 61: 439-40.

7. Plouin PF, Gimenez-Roqueplo AP. Pheochromocytomas and secreting paragangliomas. Orphanet J Rare Dis 2006; 1: 49.

8. Grace M, Cheruvathur P, Sinni, Sasi L. Secondary hypertension: A rare cause. Indian J Endocrinol Metab 2011; 15: 48-50.

9. Reisch N, Peczkowska M, Januszewicz A, Neumann HP. Pheochromocytoma: presentation, diagnosis and treatment. J Hypertens 2006; 24: 2331-9.

10. Prejbisz A, Lenders JW, Eisenhofer G, Januszewicz A. Cardiovascular manifestations of pheochromocytoma. J Hypertens 2011; $29: 2049-60$.

11. Pacak K. Preoperative management of the pheochromocytoma patient. J Clin Endocrinol Metab 2007; 92: 4069-79.

12. Arai T, Hatano Y, Ishida H, Mori K. Use of nicardipine in the anesthetic management of pheochromocytoma. Anesth Analg 1986; 65: 706-8. 